\title{
A dramatic case of non-episodic angioedema with eosinophilia
}

\author{
M Clements-Baker*, R Borici-Mazi \\ From Canadian Society of Allergy and Clinical Immunology Annual Scientific Meeting 2009 \\ Halifax, Canada. 22-25 October 2009
}

Gleich Syndrome, also known as episodic angioedema with eosinophilia, was first described in 1984 by Gleich et al as a rare cause of hypereosinophilia. Angioedema with eosinophilia can be classified into 2 types: episodic or non-episodic. We present a dramatic case of non-episodic angioedema with eosinophilia in a young male.

A 34 year old construction worker, presented to the emergency department in the summer of 2008 complaining of generalized fatigue, muscle aches and upper extremities swelling with no evidence of skin rash. He had been vacationing at his trailer in Southeastern Ontario, but denies any trauma, bug bites or new medications. Initial investigations showed a marginallly elevated WBC and eosinophils. He was discharged home on comfort measures only, but returned to hospital 2 days later complaining of shortness of breath, pleuritic chest pain and rapidly progressing generalized edema involving his face, neck, arms, upper chest and abdomen. His blood work showed markedly elevated WBC and eosinophilia peaking at $62.6 \times 10(9)$ cells/L and $45.70 \times 10(9)$ cells/L, respectively. A CT scan of the chest revealed bilateral pleural effusions, where as a cardiac MRI demonstrated a small pericardiac effusion. A bone marrow aspiration and biopsy confirmed marked hypereosinophilia with no leukemic features. A triceps muscle biopsy demonstrated marked eosinophilic infiltration. This patient responded well to oral steroids started at $1 \mathrm{mg} / \mathrm{kg}$ with a slow tapering regimen and developed no permanent organ damage. Thorough work up failed to identify any cause for his condition, including a lack of FIP1L-PDGFRA gene. His WBC and eosinophil count returned to normal values in 3 months with no recurrence of angioedema for one year.

Department of Medicine, Queens University, Kingston, Ontario, Canada

\section{Conclusion}

This is the first case report of rapidly progressing nonepisodic angioedema with eosinophilia associated with mediastinal involvement in a young male.

Published: 12 May 2010

doi:10.1186/1710-1492-6-S1-P23

Cite this article as: Clements-Baker and Borici-Mazi: A dramatic case of non-episodic angioedema with eosinophilia. Allergy, Asthma \& Clinical Immunology 2010 6(Suppl 1):P23.

\section{Submit your next manuscript to BioMed Central and take full advantage of: \\ - Convenient online submission \\ - Thorough peer review \\ - No space constraints or color figure charges \\ - Immediate publication on acceptance \\ - Inclusion in PubMed, CAS, Scopus and Google Scholar \\ - Research which is freely available for redistribution \\ Submit your manuscript at www.biomedcentral.com/submit}

